\title{
Socio-Economic Manifestation Dealing with a Proven Green Pit Viper (Cryptelytropssp.) Envenomation- A Case from Nalagad Municipality, Jajarkot, Karnali Province, Nepal
}

\author{
Badri Baral 1,2* (D), Ganesh Bahadur Magar ${ }^{2}$ (D), Karan Bahadur Shah ${ }^{3}$ (D)
}

\begin{abstract}
${ }^{1}$ Nepal Environmental Research Institute (NERI), Tarakeshwor 9, Kathmandu 44610, Nepal

${ }^{2}$ Nature Conservation Initiative Nepal (NCI-Nepal), Gokarneshwor 5, Kathmandu 44602, Nepal

${ }^{3}$ Himalayan Nature, Kathmandu 44600, Nepal
\end{abstract}

\begin{abstract}
This case documents envenomation by a Green pit viper (Cryptelytrops sp.), a species found in South and Southeast Asia that causes the majority of venomous snakebites among Southeast Asian pit vipers. The proven life-threatening cases described in published literature, however, are sparse. We report a case of noticeable envenomation due to confirmed Green pit viper, Cryptelytrops $s p$. bite in Jajarkot. This is the first known reported case of such a bite from Jajarkot in Nepal. This case highlights the urgent need to improve diagnosis, monitoring, and supportive care for snakebite victims in Nepal.
\end{abstract}

Keywords: snakebite, envenomation, antivenom, pit viper

\section{Correspondence:}

Badri Baral

Address: Nepal Environmental Research Institute (NERI),

Tarakeshwor 9, Kathmandu 44610,

Nepal and Nature Conservation

Initiative Nepal (NCI-Nepal),

Gokarneshwor 5, Kathmandu 44602, Nepal

Email: badribaral2071@gmail.com

Received: 26.08.2021,

Accepted: 12.11 .2021

https://doi.org/10.29333/jcei/11514

\section{INTRODUCTION}

The Asian pitvipers of the Crotalinae subfamily are included in nine genera: Calloselasma, Deinagkistrodon, Garthius, Gloydius, Hypnale, Ovophis, Protobothrops, Cryptelytrops, and Zhaoermia) [1]. Among the seven pit viper species with definitive distribution records in Nepal (i.e, Gloydius himalayanus, Ovophis monticola, Cryptelytrops albolabris, C. septentrionalis, Protobothrops jerdonii, Protobothrops himalayanus, and Himalayophis tibetanus), pit vipers of Cryptelytrops spp. are common, medically relevant snake that is distributed in the lowlands, hills, and lower ranges in the mountains of Nepal [2]. Green pit vipers appear to cause a large proportion of all cases of snake bite envenomation in Nepal [2]. Despite this, little is known about these pit viper species diversity and the burden and effects of their envenomation. There are no published details on the systemic envenomation by pit vipers in Nepal. Herein, we present the photographic manifestations of a proven Cryptelytrops sp. envenomation that occurred in the northeastern hills of Jajarkot district, Nepal. This is the first known reported case of such a bite from the district in Nepal.

\section{CASE REPORT}

On 21 August 1994, a 19-year-old (then), relatively healthy married woman from Nalagad Municipality in the north-eastern hills of Jajarkot district was bitten by a Green Pit Viper (Cryptelytrops sp.) in between her index finger and middle finger of the left hand at 7:45 a.m. when she was collecting fodders for the livestock. She was cutting down branches of a small dense fodder bush by holding a sickle in one hand and holding the branches by other hand when the unfortunate incident occurred. Although the culprit was resting on the bush branches but she did not notice it. She immediately applied a loose ligature by using her hairband (made from cotton threads) on the wrist.

We have identified the snake that inflicted the envenomation as Green Pit Viper, Cryptelytrops sp. from the fact that this species is known as Hareu Kano by the local villagers. After arriving at the house two distinct fang marks with bleeding and swelling of the wrist, back of the palm, and 

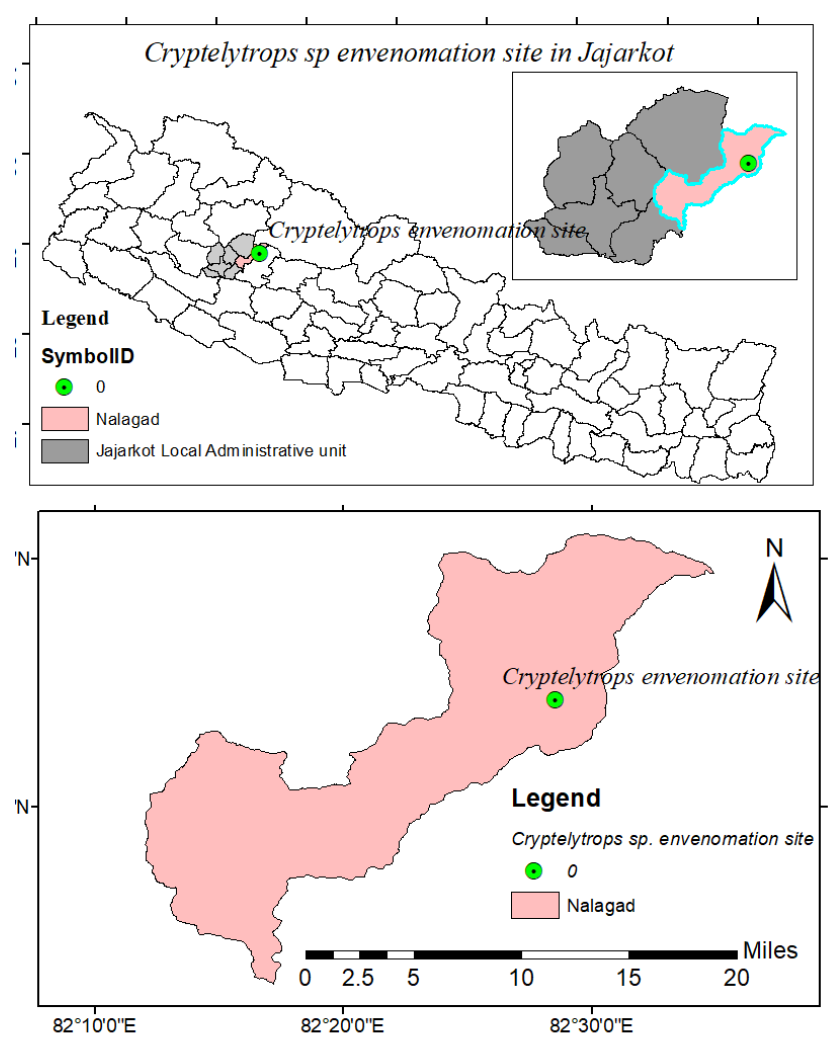

Figure 1. Cryptelytrops $s p$. envenomation site in Nalagad Municipality, Jajarkot, Karnali

the fingers were observed. About $4.5 \mathrm{hr}$ postbite, the swelling extended up the forearm to the elbow. She then felt coordination and balance difficulties and tingling (paresthesia) in her affected arm. As a result, she was working only with her normal hand. As, the snakebite incident took place away two hours walking from her house in the rural area, there was no chance of ambulation. She had to walk to reach her house so she had unknowingly splinted her affected limb below the heart level. She was not taken to any hospitals until one week post envenomation. As, she belonged to poor rural superstitious family, her family had more superstitions and faith in herbalists, faith healers, shamans etc. and she got health care from local traditional indigenous healers of Tatargaad, Nalagad area. In course of the treatment, the traditional healers chanted incantations/mantras, attempted to suck venom from the wound by applying the cloacal sphincter of a live vultures. Her husband captured live Himalayan Vultures (Gyps himalayensis) to collect their cloacal sphincter when they were feeding on a carcass.

But all those traditional healing methods could not improve her pity condition, the flesh in her hand started rotting and producing foul smell. Flies' infestation induced microbial contamination led to a purulent discharge from her hand. This made her husband each day to engage in washing her clothes. Other people stopped her nearby approach as she was smelling too bad. When her condition highly deteriorated, she was taken to a hospital in Rarijyula, Rukum district after a week. The doctors of the hospital removed the probable microbial contaminated portion and excised abscesses.

At the time of this incident, she had one son and a newly born baby girl. She was asked to stop breast feeding to her newly born baby by her family members. Since there was shortage of fodder due to her bed ridden condition and also due to urgent need of money the family sold their two milk producing buffaloes. The buyer seized the opportunity to buy their buffaloes then at the rate of NRs 15,000 (appx. US $\$ 126.05 /$-) which was undervalued by NRs 10,000 (approx. US $\$ 84.04 /-)$.
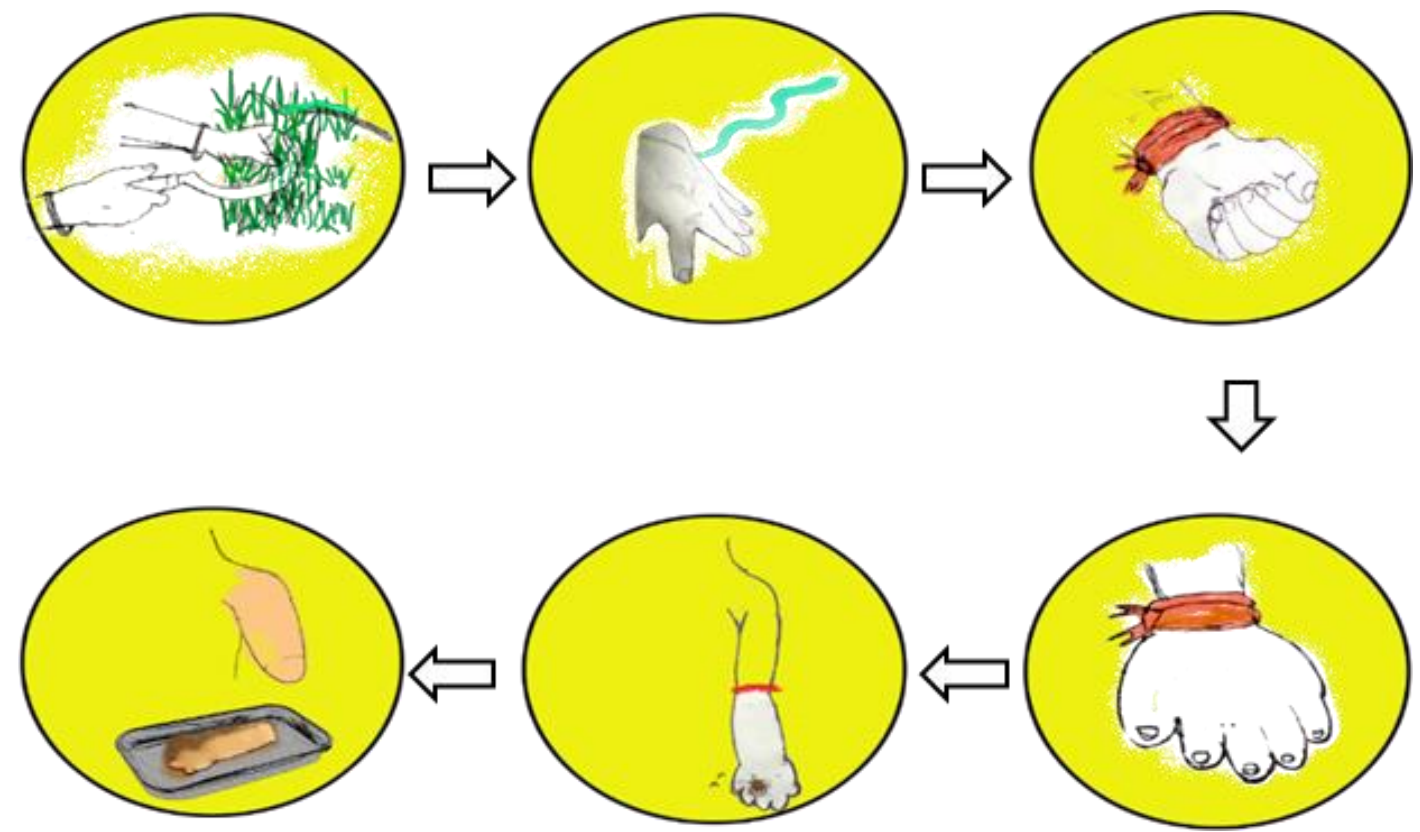

Figure 2. Flow chart illustrating hand amputation after envenomation 


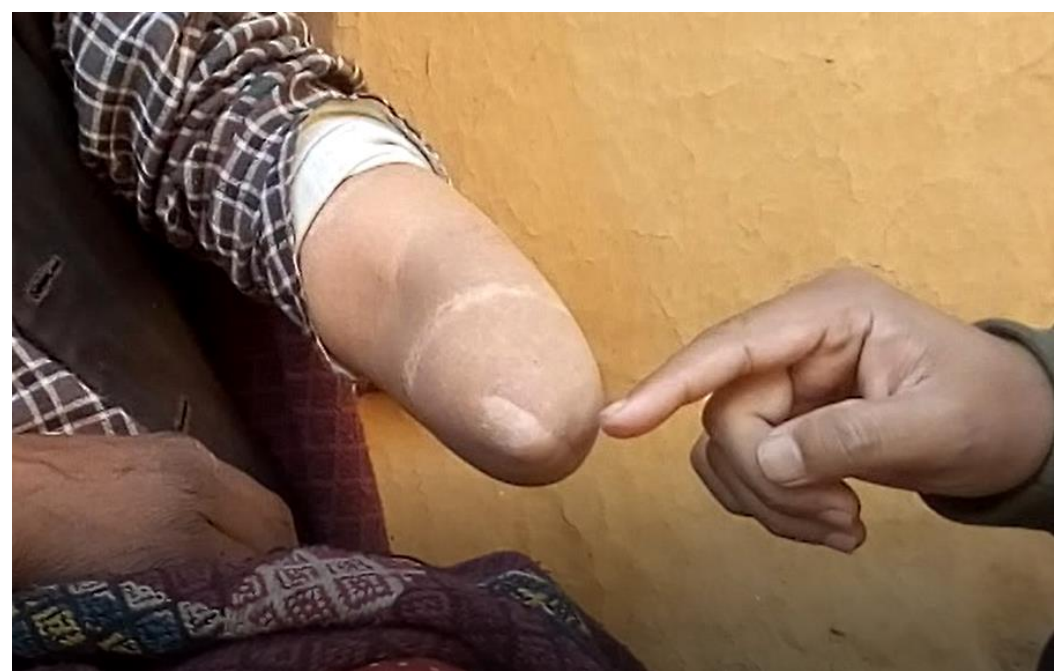

Figure 3. Amputated hand due to consequences of green pit viper envenomation of the victim. Photo: Ganesh Bahadur Magar

The couple with their children and other logistics left the village and after walking six days arrived Pokhre of Salyan district. Finally, the couple reached India for the treatment after about six and half months of envenomation and stayed there for another nine months. In India initially she was treated with antibiotics and a proteolytic enzyme. Then she was referred for surgical consultation at a higher center immediately after initial evaluation in the emergency department of the hospital. Her left hand was amputated on 19 March 1995 almost after seven months due to Green pit viper envenomation developed complication. Besides the victim losing her arm, in overall, the poor family had spent NRs 70000.00 (approx. US \$ 588.2/-) in the treatment.

\section{DISCUSSION AND CONCLUSION}

There is no specific pitviper antivenoms in Nepal [2,3]. The effectiveness of the frequently used Indian polyvalent snake antivenoms and a special Thailand's green pit viper antivenom on green pit viper venoms still needs to be determined [2]. Similar conservative treatment of pitviper envenomations without using specific antivenom was practiced in this case as well which were practiced elsewhere in Nepal [4,5].

Since the economy of local people residing in northern jajarkot is low and based on transhumance practice of animal husbandry, morbidity and mortality related incidents of snakebite in Jajarkot are considerably higher but still they are neglected in terms of snakebite related precaution and treatment. Lack of transport facilities and snakebites treatment centers in the midhills of the country and availability of road access leads to delay or inability in seeking medical treatment by many victims in rural setup. Likewise, poor rural people living in mountains are somewhat governed by superstitions which may lead to unnecessary mortality and morbidity.

Training on proper snakebites handling and treatment to the personnel engaged in the emergency healthcare management in the local health service centers including local hospitals, adherence to the available standard protocol, development of national guidelines based on the clinical trials would help to eliminate this disparity and result in effective management of the snakebites.

Author contributions: All authors have sufficiently contributed to the study, and agreed with the results and conclusions.

Funding: No funding source is reported for this study.

Acknowledgements: We thank Mrs. Tara Kamini, patient for providing her data and to allow us take the photos. We appreciate the anonymous reviewers for their valuable suggestions and comments on the manuscript.

Declaration of interest: No conflict of interest is declared by authors.

\section{REFERENCES}

1. David P, Vogel G. An updated list of Asian pitvipers and a selection of recent publications. In: Visser D (ed.), Asian Pitvipers. Breeding Experience \& Wildlife, 2015: 545-76.

2. Shah KB, Tiwari S. Herpetofauna of Nepal: A conservation companion. IUCN - The World Conservation Union, Nepal. 2004. 237 pp.

3. Shrestha BR, Pandey DP, Acharya KP, et al. Effective, polyvalent, affordable antivenom needed to treat snakebite in Nepal. Bull World Health Organ. 2017; 95: 718-9.

4. Bhatt N, Singh A, Sharma SK. Management of pit viper envenoming without antivenom: a case series. Am J Trop Med Hyg. 2020; 102: 1440-2. doi: 10.4269/ajtmh.20-0035.

5. Pandey DP, Ghimire A, Shrestha BR. Retrospective documentation of a confirmed White-Lipped Green Pit Viper (Trimeresurus albolabris Gray, 1842) bite in the south-central hills of Nepal. Wilderness Environ Med. 2019; 30: 79-85. doi: 10.1016/j.wem.2018.11.001. 